\title{
The Implementation of Learning Management System Model in Vocational School
}

\author{
Hasbullah \\ Department of Electrical Engineering Education \\ Faculty of Technology and Vocational Education \\ Universitas Pendidikan Indonesia \\ hasbullahmsee@yahoo.com
}

\begin{abstract}
This study aims to develop and to implement the Learning Management System (LMS) model in improving learning outcomes in Electronic Measurement (EM) subjects for students of vocational school in Bandung. LMS is an online learning system or e-learning, which is a web-based learning management application that can facilitate students/learners to learn in a virtual classroom. This research employed research and development approach, which led to a cycle based on studies and research findings were then developed to produce a model of the product. To find an increase in students' learning outcomes in the cognitive aspects, the quantitative approach was done with a technique that used a quasi-experimental pretest-posttest group design. The experimental group was given a learning treatment with LMS implementation, while in the control group was treated with conventional learning models approach in the classroom. The data obtained in this study were from the results of the pretest and posttest and then analyzed with an average ratio test (t-test) and test score to gain the difference. The results of this study indicated that vocational students' achievement in EM subject by using LMS applications models were higher than the students' learning outcomes by using conventional learning models. Based on this analysis, it can be concluded that LMS model can improve students' learning outcomes in EM subject at vocational school in Bandung.
\end{abstract}

Keywords- E-learning, electrical measurement, learning management system, vocational school

\section{INTRODUCTION}

One policy learning and vocational technology program that echoed the government is learning that utilizes the advantages of Information and Communication Technology (ICT). Utilization of ICT or the Internet in the world teaching the world teaching will help increase the quantity of students. Learners will be more and more over the Internet that can be embraced. In addition to the increase in quantity, the same thing also applies to the quality. As described above, the increase in the quantity of learners can degrade the quality of teaching is obtained. Procurement of Internet technology, can be one of the anticipatory against the possibility.

The use of educational technology in learning such as elearning or LMS offers many benefits and advantages are obtained, both for students and teachers to help them to learn to use interactive and collaborative engineering [1]. In particular, the use of the internet currently offers tools and application packages for teachers or educators that can be used at all stages of teaching and learning, and tools and applications as it can increase the effectiveness and efficiency of teaching [2].

One way that students' interest towards vocational subjects at high EM is changing the learning process is carried out so far. Among the changes can be made is the use of models in the learning process EM. Learning EM recommended using a model that has the potential to add insight and context of learning and to improve student learning outcomes. Electronic books (e-books), articles, slides, films, radio, television, computers with CD-ROM and Internet connection can be used to access a variety of information about the material from various sources from around the world. That is, the learning processed EM already be open by using a model of the elearning or learning management system. In designing LMS is desirable and useful is a system that is simple, personal, and fast. Simple system that will allow participants to take advantage of existing technology and the menu, with the ease at which the panel is provided to reduce the time of the introduction.

There are some tools that are used to manage the administration of e-learning or LMS including using Moodle, ATutor, Dukeos. Therefore it is necessary to make an LMSbased learning model on the subjects of electrical measurements at vocational school more dynamic and interactive way to improve student learning outcomes.

\section{METHOD}

The method used in this study is the approach to research and development because this research aims to develop a model of learning in vocational schools to improve student learning outcomes in subjects mastered measurement electronics components. Locations in this study were three vocational high school residing in the city of Bandung, namely. As a source of data in this study was students of class XI vocational school in engineering competence power installations program with the total students of 107 and 6 teachers.

Stages of research development according to Borg and Gall includes the following steps: 1 . research and information collecting; 2. planning ; 3. develop preliminary form of product; 4 . preliminary field testing; 5 . main product revision; 6. main field testing; 7. operational product revision; 8. operational field testing [3]. 


\section{RESULTS AND DISCUSSION}

LMS model development to improve student learning outcomes in subjects of electrical measurements in vocational school using the software application Moodle learning begins with a literature study in an effort to seek a referral form the basic theories and principles of model development. Model LMS is a learning model that utilizes a software application used to create on-line learning materials or lectures and managing web-based learning activities and results [4]. Implementation of LMS learning models of electrical measurements on subjects as described six stages, including that: (a) the kinds and teaching materials; (b) specify the design of a model of the LMS; (c) specify the format and links of online learning; (d) to test the design of the LMS that was made; (e) organizing model of LMS with good and true; and (f) prepare criteria for assessment or evaluation.

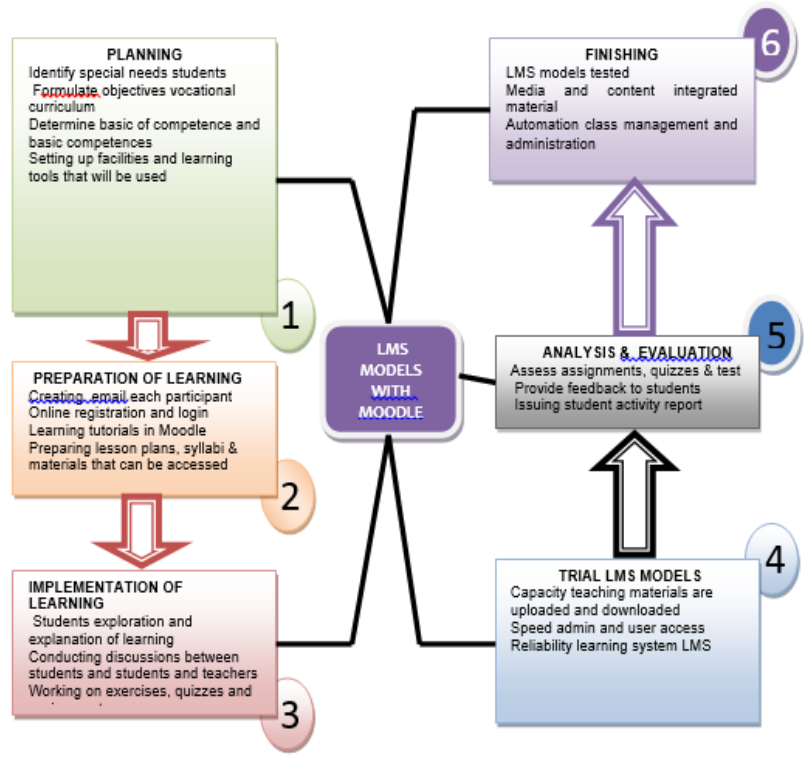

Fig. 1. Moodle LMS-Based Learning Model

\section{A. Conditions of Learning Process on Electrical Measurement of Subjects}

In vocational lack of innovation and creativity in learning Electrical Measurement teacher at Vocational School is the focus of researchers. This can be seen from some of the indicators that include the use of instructional materials by teachers prefer teaching materials that are already available on the market either book, job sheet, LKS and others, both of which are used by students and teachers, while to develop their own teaching materials still comparatively less this is because teachers have had the pleasure of using instructional materials for which they are used regardless of the extent of development of the material is given dive. Other findings that describe the condition of learning Electrical Measurement in Vocational School are the persistence of the value of student learning outcomes under the passing standard; students find it difficult to find references that can assist them in understanding learning, when they do not understand or want to ask to find solutions to the problems in learning or in the lab, activities are shame and fear to ask the teacher, in addition to the students also felt saturated with such subjects as using methods that are tedious, they expect something new in the teaching and learning activities in subject's matter.

While the findings relating to the evaluation system in vocational learning, learning to evaluate teachers tend to use the evaluation that emphasizes on various aspects ranging from aspects of ability (cognitive) aspects of attitude, discipline and student behavior (affective) as well as the capability to perform lab in workshops or laboratories (psychomotor). The whole aspect of the basis for the final assessment of students, so the student who has met the passing standard is entitled to earn as evidence that the students have passed a specific outcome. Meanwhile, for students who have not met the graduation, they are given the opportunity to do a repair (remedial) to exceed the standards set graduation. Based on these issues and to cover the deficiencies that exist in face-to-face classroom learning, the use of LMS learning model is considered an alternative solution to the problems faced by students in learning and mastering the subject matter. Besides, the model developed Moodle-based LMS has been equipped with various devices and learning media that can be accessed online, from lesson plans and syllabi, teaching materials, instructional models, instructional media and learning evaluation system that has been integrated in a system that is Learning Management Systems.

\section{B. Characteristics LMS Learning Model to Improve Learning Outcomes in vocational Electrical Measurement of Subjects Based on the development and implementation of the LMS models used.}

In vocational education, it can be found miraculous matters relating to the advantage of use Moodle as an LMS-based application that can be used in learning. LMS is a software system to virtualize conventional teaching and learning process. How classroom management, manufacture materials or content, discussion forums, assessment system (report cards), online examination system and all the features associated with the management of the learning process. LMS is also a platform (work plan/program) for the development of e-learning, because it has many functions that are not limited to the distribution of learning materials, but also in terms of management and evaluation of learning outcomes. LMS many are the open source, so that we can use to easily and inexpensively for built in school or at university.

In the LMS models developed in this vocational school, all things learning tools available on conventional learning, ranging from the syllabus, lesson plans, learning materials, tools, materials and learning resources and assessment and evaluation is available on the LMS system. With the availability of facilities and learning resources that can be accessed online, students no longer have difficulties when they want to know and learn a particular matter or subject. Source of teaching materials available in full of conduct discussions and question and answer with fellow students and teachers to make students more motivated to implement interactive learning and not boring. First, the model developed LMS should support the institution, which in this case education office or principal as the authorities in policy making, it certainly concerns the implementation of the policy implementation model of elearning or LMS at school, because the Principally this online 
learning system requires a lot of tools or facilities to be provided by the institution or school. It is therefore, impossible without institutional support on-line learning model can be held properly. Second, development of courses, the LMS model development course be one of the characteristics that can support learning effectiveness. Various materials have been available it can be used with the students how to read, understand and develop materials and provide opportunities for learners to construct new knowledge. They are required to actively add to their own knowledge. Third, teaching and learning, the LMS models developed this learning process is more on the use of information technology such as computers equipped with means of telecommunication (the Internet, intranet, extranet) and multimedia (graphics, audio, video) as a medium the main delivery of content and interaction between faculty (teachers) and learners (students). Moodle LMS-based learning model has resulted in a change of culture in the context of learning to learn. There are several important components in building a culture of learning by using LMS models, among which: (a) students who are the object of study is required to learn independently in accordance with the various approaches so that students are able to direct, motivate, organize themselves in learning; (b) teachers develop knowledge and skills, facilitating learning, studying and understanding the things that are needed in learning; (c) the availability of adequate infrastructure so that the learning process can be run properly; and (d) a creative administrator and preparation of infrastructure in facilitating learn. Fourth, support for students, the LMS model student support to be one thing that is a major concern, due to the absence of a continuous activity that students undertake learning activities, which started from the register (login) as course participants or subjects, upload content and learn, spell out tasks, quizzes and tests as well as an on-line discussion forum or chat through the facilities' available LMS. With this model of on-line learning student is required to learn independently in accordance with the various approaches so that students are able to direct, motivate, organize themselves in learning. Fifth, evaluation and assessment, there are other advantages over the model developed LMS is a system of evaluation that can evaluate or as needed. Teacher or the teacher can give the student a direct assessment of the activities that have been implemented, and can also provide feedback on a variety of learning activities that students have done, ranging from tasks, quizzes, tests and other activities. With a system of evaluation or value that can be accessed directly.

C. Improved responsiveness and motivation of students in Electrical Measurement of subjects due to the application of the Learning Management System at Vocational School

Implementation of LMS learning models in vocational generally can increase a student's motivation to learn the material and complete the competency standards expected. Students feel the LMS learning models such as these give a different feel and a more interesting and interactive so monotonous impression learner and only one direction can be eliminated with the LMS models that provide a more dynamic learning environment and meaningful. In the use of Moodle as an LMS with the students learning media ME benefit and ease in understanding competency standards specified as the main component that influences the success of learning, as a source of teaching material and as a study guide for students. Acceleration can be felt by students learning it, they can access the materials provided teachers freely and independently without the constraints of space and time, students can also have two roles at the same time, being a student and also a guest speaker at the forum was made available in the LMS and to discuss the material deemed necessary discussion and deeper. LMS learning model requires students to learn independently and develop his abilities as well as full responsibility for learning. LMS learning environment with student role will force a more active role and make design and material to the business and seek their own initiative.

\section{DISCUSSION}

The development of learning model is an attempt to obtain the success of the learning process; success can be measured by the impact on student learning in the form of changes in behavior, attitude, learning independence and achievement of learning outcomes. Model Learning Management System (LMS) is a model of systematic and structured learning and going through the stages or steps that lead to the achievement of learning outcomes and in this case the expected competencies. This is in line with what is proposed by Gunter et al. that the learning model as a model of instructional procedures performed with a systematic step by step, and that leads to learning outcomes [5]. According to Joyce \& Weil suggested that the learning model as a conceptual framework that is used as a guide or instructions to implement the learning process [6]. Thus, the model LMS is a conceptual framework that describes stages systematically arranged in manage and organizing learning experiences in order to achieve the expected learning objectives.

Involve various components of the learning is in line with the proposed Carrey et al. that learning is built with several components, among others: (1) identify the learning objectives; (2) the analysis of learning; (3) learning and environmental analysis; (4) record performance objectively; (5) develop assessment instruments; (6) develop learning strategies; (7) selecting and developing teaching materials; (8) an evaluation of learning; and (9) revise learning [7].

The occurrence of improving student learning outcomes after using the model-based LMS Moodle as a learning media on subjects EM, proving the theory of learning media one of the principles of the theory of Edgar Dale cone of experience (cone of experience). Dale explains that the use of instructional media more concrete or with direct experience of the message (information) on the learning process will be submitted to the student teacher conveyed properly [8]. But on the contrary, if the use of instructional media increasingly abstracts the message (information) will be difficult for students to be accepted, in other words, students have difficulty in understanding and digesting what is delivered by the teacher. With increasing student learning outcomes also indicate that increasing students' mastery of subject learning materials EM In its implementation, the LMS learning models in SMK not only has the advantage of a variety of sides that can be said to be a contributing factor but also has obstacles or barriers that 
arise when the model is implemented. Various factors, among others, are supporting the learning facilities.

In connection with the implementation of the LMS, this model has the advantage besides, there are also factors that constrain the implementation in schools, which are not yet available tools/school facilities to the maximum. Schools only have a computer and Internet connection in a particular area such as the principal's office, teachers and administrators so that students experience difficulties when they want to implement Internet-based learning or e-learning. Other constraints is the readiness and willingness of teachers to further develop learning still relatively less, although the teachers have been given the education and training on how North-based learning and information and communication technology (ICT), but the implementation is only a small percentage of teachers who want to apply it all; they enjoy learning, which uses conventional models that were done.

The results of a study of learning effectiveness and improvement of learning outcomes by using the model LMS or e-learning in line with the theories of the experts who first develop and conduct research on the LMS models. Among them, Cisco promoted that philosophical model of learning LMS is First, Model LMS or e-learning is the delivery of information, communication, education, on-line training [9]. Second, LMS provides a set of tools that can enrich the learning value of the conventional (conventional learning models, the study of textbooks, CD-ROMs, and computerbased training) to meet the challenges of the globalization. Third, the LMS is not meant to substitute for the conventional model of learning in the classroom, but reinforce the learning model through content enrichment and development of educational technology. Fourth, the capacity of students varied greatly depending on the content and form of delivery. The better the alignment between the content and delivery tools with models of learning, so it is best the capacity of students who in turn will give best results based on the study and the description above, clearly the LMS model is a learning model that is the result of research and development in the process of learning EM has a goal to improve student learning outcomes in vocational school.

\section{CONCLUSION}

1. Utilization Model Learning Management System (LMS) in learning to EM can improve student learning outcomes. Implementation Moodle-based LMS models provide an online learning environment that is independent, so that teaching and learning to become more effective and conducive learning climate that is conducive to enhance the absorption of students or learners of the material being taught, so that the learning outcomes have increased significantly.

2. General conditions EM learning in vocational high schools going pretty well in terms of various aspects, including learning implementation plan, teaching materials, instructional models, instructional media, and evaluation of learning; however, there are still difficulties associated with the development the various aspects of making learning effective EM still not running. Based on the constraints faced by them and to complement the existing deficiencies in the in person classroom learning, the LMS learning models use an alternative solution to the constraints faced by students and teachers in learning and mastering the subject matter.

3. Characteristics of the LMS models were developed using the Moodle software is one of the best open sources LMS software with premium features and support according to the needs of education and learning. Characteristics of LMS-based model are also still considering pedagogical aspects that include six cases namely: (a) the support institutions of learning with LMS implementation; (b) the development of the subject; (c) the creation process of teaching and learning; (d) the structure of the subjects; (e) the support of students or learners; and (f) the availability of facilities for evaluation and assessment.

\section{REFERENCES}

[1] Concannon, F., Flynn, A., \& Campbell, M. (2005). What campus-based students think about the quality and benefits of e-learning. British Journal of Educational Technology, 36(3), 501-512.

[2] Cavus, N. (2015). Distance Learning and Learning Management System, Procedia, Social and Behavioral Sciences 191 ( 2015 ) 872 877.

[3] Borg, W. R. \& Gall. (2003) . Educational Research: An Introduction, Fifth Edition. New York: Longman.

[4] Ellis K, R. (2009). A Field Guide to Learning Management System, Published the American Sociedty for Training and Development (ASTD) Learning Circuit.

[5] Gunter, A. L., et al. (1990). Instruction a Model Approach. London: Allyn and Bacon.

[6] Joyce B \& Weil M. (2000), Models of Teaching, 6th Edition, Engle Wood Cliffs N.J: Prentice Hall International. Inc.

[7] Carey, L. Dick W \& Carey, J. O. (2005). The Systematic Design oflinstruction. Boston: Harper Collin College Publisher.

[8] Dale, Edgar, (1994) Audio Visual Methods in Teaching, New Yorg: Holt, Rinehart and Winston Inc. The Dryden Press.

[9] Cisco (2001), e-learning: Combine Communication, Education, Information and Training. http://www.cisco.com/warp/public/10/wwtraining/elearning. 